\title{
Species-specific phytoplankton growth rates via diel DNA synthesis cycles. II. DNA quantification and model verification in the dinoflagellate Heterocapsa triquetra
}

\author{
Jeng Chang, Edward J. Carpenter
}

Marine Sciences Research Center, State University of New York, Stony Brook, New York 11794, USA

\begin{abstract}
The DNA content of individual cells, after being stained by a DNA-specific fluorescent dye, was quantified by a TV camera-based microfluorometry system. Under proper dye concentrations, fluorescence intensity of a stained nucleus was in proportion to the amount of nuclear DNA. Durations of diel cell cycle phases were estimated with DNA histograms from 2 partially synchronized cultures of the dinoflagellate Heterocapsa triquetra. Estimates of growth rate were calculated from phase durations and compared to the growth rates estimated by cell counts. Growth rates calculated by various mathematical procedures and sampling intervals were similar, and the calculated growth rate via DNA synthesis gave a reasonably good estimate of the rate calculated by increase in cell density. This technique is promising in its application to species-specific growth rates in the field.
\end{abstract}

\section{INTRODUCTION}

Mitosis has been the primary terminal event used in the cell cycle concept for measurement of speciesspecific growth rates (Weiler \& Chisholm 1976, Coats \& Heinbokel 1982, Elser \& Smith 1985). Since durations of cell cycle events such as the $G 2$ phase are much longer than the mitotic $(M)$ phase, combining some of them (i.e. $S+G 2+M$ ) can form a longer terminal event (Mitchison 1971). Such an approach could improve the accuracy of growth rate estimation and may require less samples for each measuring cycle (McDuff \& Chisholm 1982). In addition, a mathematical derivation indicates that it is possible to estimate the duration of terminal events for a partially synchronized culture without a second independent calibration (Carpenter \& Chang 1988). To evaluate the performance of the proposed method, we conducted experiments on a laboratory-cultured dinoflagellate, Heterocapsa triquetra, and compared our growth rate estimation with another independent growth rate method.

In order to use one or several cell cycle stages as the terminal event, the DNA content of cells must be measured to decide their position in the cell cycle. The discovery of quantitative, DNA-specific, fluorescent dyes provides a convenient way to quantify DNA content for individual cells. Among these dyes, 4'6-diamindino-2-phenylindole (DAPI) is an especially superior one for our purpose (Williamson \& Fennell 1975, Otto \& Tsou 1985). DAPI combines with A-T pairs in DNA molecules specifically, and this DAPI-DNA complex gives a strong blue fluorescence when excited with UV light (Kapuściński \& Skoczylas 1977). Since there are no A-T pairs in RNA, the use of DAPI eliminates the necessity of treating samples with RNase. In addition, the uncombined DAPI molecules give only a weak fluorescence about $1 / 10$ to $1 / 60$ of that of the DAPIDNA complex, so that cells in a staining solution can be mounted directly on a slide for measurement (Brunk \& James 1977).

Microfluorometry (Coleman et al. 1981) and flow cytometry (Yentsch et al. 1983) are 2 ways to measure the fluorescence intensity of the DAPI-DNA complex of each cell. The resultant DNA histograms are then deconvolved into $G 1, S$, and $G 2+M$ cells expressed as fractions of the population (Dean 1985). An advantage of microfluorometry over flow cytometry is that each cell can be seen and identified under a microscope. Thus, in a field sample containing many phytoplankton species, we are able to obtain a DNA histogram for 
each species. Also, microfluorometry is more convenient in measuring the DNA content of each cell for a chain-forming species. However, compared to flow cytometry, microfluorometry is slow, and its variation seems to be larger (Dolbeare 1981). The microfluorometry system used in this study is equipped with a low light television camera and a video digitizer to detect the fluorescence intensity. Compared to systems which record the fluorescence intensity with a photocell, the digital system is more convenient in subtracting the background and has a faster measuring speed. Some basic properties of this system are also presented in this report.

\section{MATERIALS AND METHODS}

A Zeiss Universal epifluorescence microscope and a Zeiss MPS microfluorometry system were used to determine the fluorescence intensity of DAPI-stained nuclei. The excitation light was generated by a mercury lamp (Osmar $\mathrm{HBO} 50 \mathrm{~W} / 3$ DC). The emitted fluorescence was detected by a DAGE MTI low-light level SIT TV camera. A frame grabber (Imaging Technology Inc., MA, USA) digitized the images coming from the SIT camera, and data were recorded by an IBM PC/XT computer (Fig. 1). Both fluorescence intensity and cross-sectional area of each fluorescing nucleus or particle were measured at the same time.

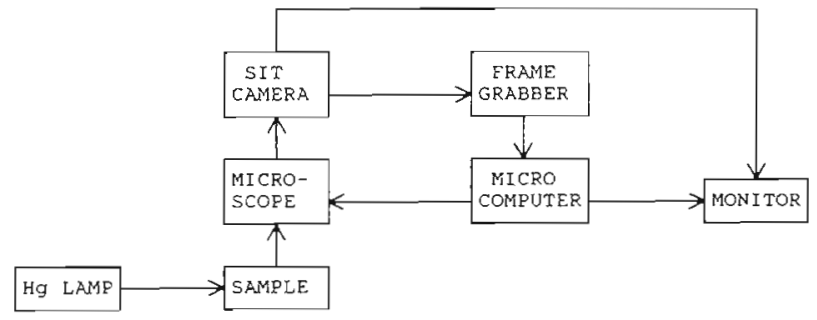

Fig. 1. Block diagram of the major components of the Zeiss MPS microfluorometry system

The variation due to the system and to staining procedures was tested using fluorospheres and chicken red blood cells (CRBC). Fluorospheres purchased from Coulter Corporation are fluorescent beads with a diameter of $5.27 \mu \mathrm{m}$. The excitation and emission wavelengths are 400 to 600 and 525 to $700 \mathrm{~nm}$ respectively. The listed CV (coefficient of variance) of their fluorescence is $1.3 \%$. The epi-fluorescence filter combination used for the fluorospheres was Zeiss filter set 487709 , but with LP 510 as the barrier filter, CRBC and DAPI were purchased from Sigma Chemical Company. A working solution containing $10 \mu \mathrm{g} \mathrm{ml}^{-1}$ DAPI was prepared in Mcllvaine buffer with $\mathrm{pH} 4.4$ and stored under $4{ }^{\circ} \mathrm{C}$. Twenty $\mu$ of $\mathrm{CRBC}$ were stained in $200 \mu$ of the DAPI working solution. Nuclei from rat livers were used to test the fluorescence linearity of the DAPI-DNA complex. Liver nuclei from 2-yr-old rats were extracted in nuclear isolation medium according to procedures described by Lee et al. (1984). In order to obtain enough nuclei to form the peak of each ploidy, rat liver nuclei were not selected randomly during measurement.

Heterocapsa triquetra clone 987 was provided by D. M. Anderson of Woods Hole Oceanographic Institution, MA, USA. Batch cultures were employed for all experiments in this study. Enriched seawater $\mathrm{f} / 2$ media (Guillard \& Ryther 1962) prepared with artificial seawater (Goldman \& McCarthy 1978) was used to ensure that nutrients were not growth limiting. Two sets of samples were obtained from 2 cultures under different growth conditions in this study. The first set of samples will be named as the 'exponential' samples since they were taken from a culture in its exponential phase. This culture was maintained under a 24 h light-dark cycle with $18,95,77$, and $0 \mu \mathrm{E} \mathrm{m}{ }^{-2} \mathrm{~s}^{-1}$ from Hour 0 to 2,2 to 12,12 to 14 , and 14 to 24 , respectively, where Hour 0 is defined as the onset of the light period (Fig. 4, insert). Temperature setting was $15^{\circ} \mathrm{C}$ during the light period and $11^{\circ} \mathrm{C}$ during the dark. Cell densities were monitored daily by counting samples in a Sedgwick-Rafter cell (Guillard 1973). In the exponential phase, hourly samples were removed for DNA histogram determination over a $32 \mathrm{~h}$ period. A sample taken at Hour 2 on Day 13 was used for all dye concentration experiments. The other set of samples, which will be named 'stationary' samples, was obtained from the stationary phase of a separate culture on L:D 12:12. The light intensity during the light period was $170 \mu \mathrm{E} \mathrm{m} \mathrm{m}^{-2} \mathrm{~s}^{-1}$; and the temperatures were set to 19 and $17^{\circ} \mathrm{C}$ during the light and the dark periods, respectively. During the $24 \mathrm{~h}$ sampling period, 13 samples were obtained with a sampling interval of $2 \mathrm{~h}$.

To stain the cells, about 0.1 to $1.0 \times 10^{6}$ cells were centrifuged at $200 \times g$ for $15 \mathrm{~min}$, and the clear supernatant was discarded. Next, $10 \mathrm{ml}$ of chilled methanol was added to extract chlorophyli for at least $8 \mathrm{~h}$ at $-15 \mathrm{C}$ (Olson et al. 1983). Before staining, methanol was removed by centrifugation, and the cell pellet was resuspended in $180 \mu \mathrm{I}$ of McIlvaine buffer ( $\mathrm{pH} 4$ 4). The cell suspension was then mixed with $20 \mu \mathrm{l}$ of DAPI working solution to achieve a final dye concentration of 0.5 to $50 \mu \mathrm{g} \mathrm{ml}^{-1}$ in the dye concentration experiment or $1 \mu \mathrm{g} \mathrm{ml}^{-1}$ in the growth rate experiment. Cells in staining solution were stored at $4{ }^{\circ} \mathrm{C}$ for at least $1 \mathrm{~h}$ before measurement. Zeiss filter set 487702 was used, but with LP 400 substituted as the barrier filter. An additional short-pass filter was inserted on the light path to remove the red fluorescence with wavelengths above $600 \mathrm{~nm}$ from any remaining chlorophyll. 


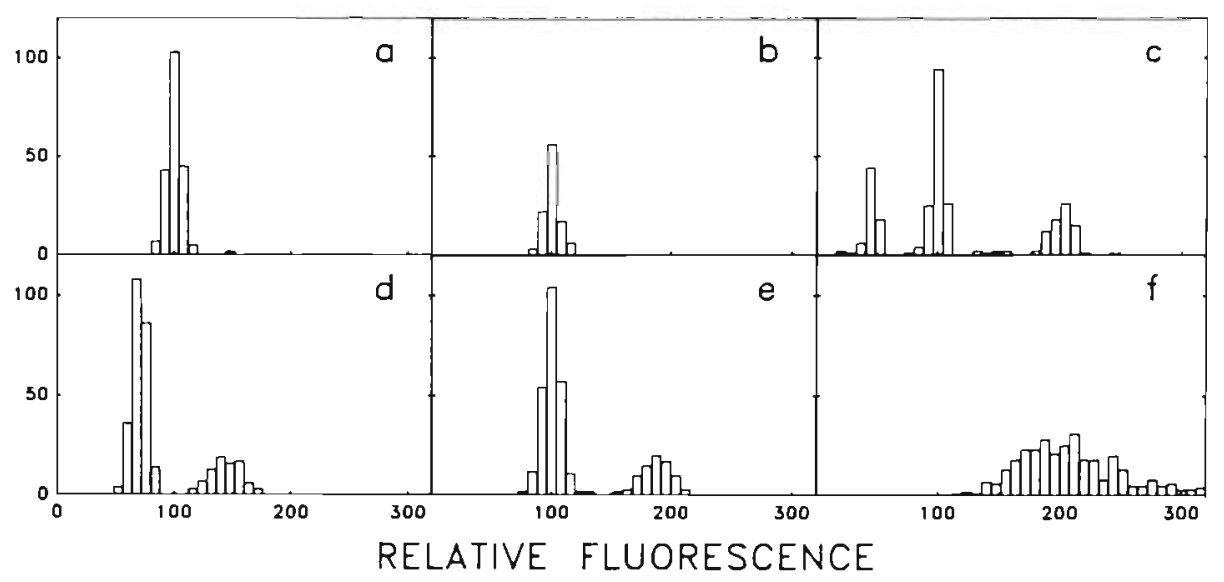

Fig. 2. Fluorescence histograms measured from various samples. The $y$-axis of each panel is (a) number of beads, or (b to f) number of nuclei. (a) Fluorospheres; (b) chicken red blood cells (CRBC); (c) rat liver nuclei. The 3 peaks from left to right are: diploid, tetraploid, and octaploid cells. (d) to (f) DNA histograms from Heterocapsa triquetra stained under (d) 0.5, (e) 5, and (f) $50 \mu \mathrm{g} \mathrm{ml}^{-1}$ of DAPI. Histograms (d) to (f) are normalized with the mode of G1 peak in (e) as 100. One of the 2 replicates is displayed for each concentration

About 320 cells of Heterocapsa triquetra were selected randomly and measured for each sample to generate a DNA histogram. Data were normalized by using the modal fluorescence of the G1 peak as 100 (Fig. 2). Since our samples came from a partially synchronized population, the parametric method proposed by Fried (1976) was applied to deconvolve histograms into phase fractions (Dean 1985). A multiple linear regression program in the SPSS statistical package (SPSS Inc.) was used to obtain the relative area uncier each normai curve by the least-square fitting technique (Fried 1976). A series of 14 normal curves were utilized at the beginning of the regression. Only curves with an area significantly greater than zero were preserved by the stepwise procedure with a $p$-toenter value 0.05 and a $p$-to-remove value of 0.10 (Sokal \& Rohlf 1981, Waterman 1974). The $G 1$ and $G 2+M$ phase fractions ( $f_{G 1}$ and $f_{G 2 M}$ ) were obtained by dividing the area of the first and last normal curve by the area under whole DNA histogram respectively. The $S$ phase fraction, $f_{S}$, was calculated from $1-\left(f_{G 1}\right)-\left(f_{G 2 M}\right)$.

In the deconvolution procedure, the $\mathrm{CV}$ of each normal curve was obtained from the scatter diagram (Fig. $3)$. In histograms with a distinctive $G 1$ peak, data points of $G 1$ cells could be isolated and the CV was computed. The CVs for all such iistograms then were averaged, and the mean CV was used for all deconvolving calculations. The position of the G1 curve was fixed at 100 . If the position of the last normal curve fell between 1.80 and 2.04 times that of the G1 curve, it was taken as the $G 2+M$ curve. In rare cases, 2 smaller adjacent normal curves would be used by the program to fit a single $G 2+M$ peak in the region mentioned above. These samples would be remeasured under the microscope and put through the calculation again. If the second sample still did not correct the problem, the inner curve was eliminated and the regression performed again to obtain the final result.

The daily mean growth rates $(\mu)$ were calculated in different ways discussed by Carpenter \& Chang (1988). First, we assumed that the instantaneous growth rate at the maximum of $f_{S}(t)$ and $f_{G 2 M}(t)$, which is denoted by $r\left(t_{1}\right)$ and $r\left(t_{2}\right)$ respectively, are zero. The sample with the highest $f_{S}$ is then identified during a $24 \mathrm{~h}$ period, and the time of obtaining this sample is used as $t_{1}$. Similarly, $t_{2}$ is found from the sample with the highest

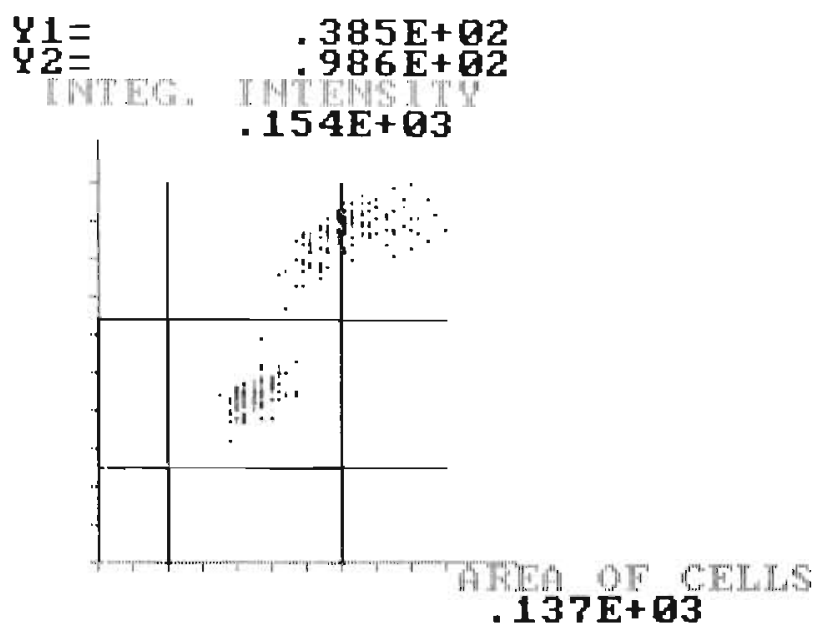

Fig. 3. Heterocapsa triquetra. Scatter diagram of a sample taken at Hour 22 of 'exponential' samples. Original output from the Zeiss MPS microfluorometry system. $x$-axis: crosssection area $\left(u \mathrm{~m}^{2}\right)$ of each nucleus; $y$-axis: fluorescence intensity with arbitrary units. A darker dot means more than 1 cell occupied the same position. G1 cells can be isolated by 2 vertical and 2 horizontal bars when $S$ cells are scarce. $Y 1$ and

$Y 2$ denote positions of 2 horizontal bars on the $y$ axis 
$f_{G 2 M}$. The total duration of $S, G 2$, and $M$ phase thus is given by

$$
T_{S}+T_{G 2 M}=2\left(t_{2}-t_{1}\right)
$$

where $T_{S}=$ duration of the $S$ phase; $T_{G 2 M}=$ duration of the $G 2+M$ phase.

A different method was to fit polynomial functions to data points of $f_{S}(t)$ and $f_{G 2 M}(t)$. A second degree, a third degree, and a fourth degree polynomial function were all computed for $f_{S}(t)$ and $f_{G 2 M}(t)$. The function with more significant $(p<0.05)$ regression coefficients was selected for further calculations. After doing this regression procedure, the duration of the $S+G 2+M$ phase was calculated either with or without iteration. Subsamples of phase fraction data, formed by omitting a data point every $2 \mathrm{~h}$ or omitting 2 data points every $3 \mathrm{~h}$, were also employed in the same procedures to test the effects of the duration of sampling interval on growth rate estimation.

Finally, the daily mean population growth rate, $\mu$, can be obtained from (McDuff \& Chisholm 1982, Carpenter \& Chang 1988):

$$
\mu=\frac{1}{\left(T_{S}+T_{G 2 M}\right) n} \sum_{j=1}^{n} \ln \left[1+f_{S}\left(t_{j}\right)+f_{G 2 M}\left(t_{j}\right)\right]
$$

where $n=$ number of samples obtained in a 24 h cycle; $t_{j}=$ time of obtaining the $j^{\text {th }}$ sample.

\section{RESULTS}

The inherent variability of the microscope system and staining procedure was relatively low. Fluorescence intensities from 205 Fluorospheres formed a single peak histogram with a CV of $6.12 \%$ (Fig. 2a; Table 1). The DAPI-stained chicken red blood cells also formed a single peak histogram which reflected the fact that CRBCs cease to divide after being formed; thus all CRBCs have an identical DNA content (Fig. 2b). The CV of CRBCs was $6.3 \%$ which is very close so that of the fluorespheres (Table 1).

The linearity of DAPI staining was checked with rat

Table 1. Coefficient of variation (CV) of fluroescence intensity measured by microfluorometry for various samples. Mean fluorescence intensity for each ploidy of rat liver nuclei are also listed

\begin{tabular}{|lrrc|}
\hline Sample & $n$ & CV $(\%)$ & Mean int. \\
\hline Fluorosphere & 205 & 6.12 & - \\
CRBC & 104 & 6.30 & - \\
Rat liver, diploid & 68 & 11.01 & 45.5 \\
$\quad$ tetraploid & 149 & 4.70 & 99.5 \\
$\quad$ octaploid & 73 & 4.38 & 200.6 \\
\hline
\end{tabular}

liver cells. Liver cells exhibit polyploidy, and mitosis was rare in the adult liver (Leeson et al. 1985). The 3 fluorescence peaks of diploid, tetraploid, and octaploid nuclei could clearly be seen (Fig. 2c). The mean fluorescence of tetraploid and octaploid nuclei was very close to 2 - and 4 -fold the mean fluorescence of diploid nuclei with a correlation coefficient of 0.9999 (Table 1). However the CV of diploid nuclei were much higher than those of tetra- and octaploid nuclei.

When stained with DAPI, the nuclei of Heterocapsa triquetra were round and emitted bright blue fluorescence. The diameter of each nucleus was about $10 \mu \mathrm{m}$. Under the epifluorescence microscope, brighter nuclei usually had a larger cross-sectional area, but from the scatter diagram (Fig.3), the cross-sectional area of $G 2+M$ nuclei seldom reaches twice of that of $G 1 \mathrm{nu}$ clei. If the final DAPI concentration used in staining was less than $5 \mu \mathrm{g} \mathrm{ml}^{-1}$, only the nucleus of each cell was stained. Both DNA histograms obtained under these 2 concentrations showed a distribution with 2 peaks, although the relative fluorescence was weaker for samples stained with a lower concentration (Fig. 2 d, e). The peak with the lower DNA content was regarded as composed of $G 1$ cells, and the other peak was regarded as the $G 2+M$ peak. Usually, such a DNA histogram, composed of 300 cells from a stained pure culture, can be obtained in $40 \mathrm{~min}$.

In general, the ratio between the averaged fluorescence intensity of $G 1$ nuclei and $G 2+M$ nuclei was around 2 , but the $(G 2+M): G 1$ brightness ratio of samples stained with the lower DAPI concentration was higher. The variation in fluorescence was also higher under the lower dye concentration. For all 4 samples, the CVs of $G 1$ and $G 2+M$ nuclei as well as the fraction of $G 2+M$ cells were similar (Table 2). When the dye concentration was increased to $50 \mu \mathrm{g} \mathrm{ml} \mathrm{m}^{-1}$, a totally different picture emerged. We observed that not only the nucleus but also the cytoplasm of each Heterocapsa triquetra cell was stained and emitted fluorescence. This increased the integrated intensity of cells tremendously and destroyed the characteristic shape of the histogram completely (Fig. 2f). The peaks for G1

Table 2. Heterocapsa triquetra. Summary of fluorescence data

\begin{tabular}{|c|c|c|c|c|}
\hline $\begin{array}{l}\text { DAPI } \\
\left(\mu g \mathrm{ml}^{-1}\right)\end{array}$ & $\begin{array}{l}\text { Mean int. ratio } \\
(G 2+M: G 1 .)\end{array}$ & $\begin{array}{l}\text { CV } \\
G 1 \\
(\%)\end{array}$ & $\begin{array}{c}C V \\
C 2+M \\
(\%)\end{array}$ & $f_{G 2 M}$ \\
\hline \multirow[t]{2}{*}{0.5} & 2.05 & 8.73 & 8.78 & 0.253 \\
\hline & 2.09 & 9.03 & 7.87 & 0.291 \\
\hline \multirow[t]{2}{*}{5} & 1.87 & 6.49 & 6.22 & 0.292 \\
\hline & 1.88 & 7.68 & 6.75 & 0.245 \\
\hline 50 & - & - & - & - \\
\hline
\end{tabular}
on DAPI-stalned samples under various dye concentrations 
and $G 2+M$ cells were no longer recognizable, and no quantitative comparison was possible with respect to other samples stained under lower concentrations.

The 'exponential' samples were taken from a culture of Heterocapsa triquetra in its exponential phase. The growth rate of this partially synchronized culture estimated by linear regression from Day 0 to 10 was $0.35 \mathrm{~d}^{-1}$ (Fig. 4, upper panel). DNA histograms from 31 hourly samples exhibited synchrony of DNA synthesis, and the cell division cycle was revealed clearly by histograms of sequential samples (Fig. 5). At the first hour after the termination of the dark period, almost no $S$ phase cells were observed (Fig. 5, Hour 1). One h later, a small broadening started to show up on the

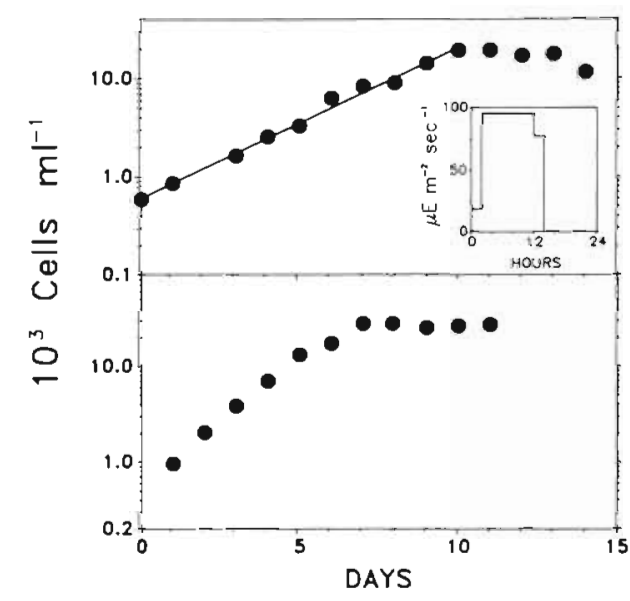

Fig. 4. Heterocapsa triquetra. Growth curve of 2 cultures from daily cell counts. Upper panel: 'Exponential' samples taken between Day 8 and 10. Solid line is the linear regression for population densities from Day 0 to 10 with $r=0.996$. Insert shows light regime for each day. Lower panel: 'Stationary' samples obtained between Day 8 and 9 right of the base of the G1 peak (Fig. 5, Hour 2), indicating that some cells in the population began to synthesize new DNA. As more and more DNA was synthesized, the mean DNA content of the cohort of cells which entered the $S$ phase at about the same time became high enough so that these cells finally formed a third peak in the histogram of Hour 10 (Fig. 5). The position of this third peak clearly identified itself as being composed of $S$ cells. From Hour 11 to 14 , very few or no cells were released from the $G 1$ peak, and the $S$ peak moved toward the $G 2+M$ peak gradually due to the continuous increase in cellular DNA content. After the cell cohort had arrived at the $G 2+M$ phase completely, the population seemed to enter a preparation stage for mitosis for about $5 \mathrm{~h}$. During this period, both $G 1$ and $G 2+M$ peaks did not have any obvious activity. Starting from Hour 20, which was $6 \mathrm{~h}$ after the onset of the dark period, some $G 2+M$ cells performed mitosis. As a result, the $G 2+M$ peak became lower and lower, but the height of the $G 1$ peak increased significantly at the same time due to the joining of newly divided cells (Fig. 5, Hour 20 to 24). Next, G1 became the dominant peak again, and a newly formed $S$ peak could be found at the base of $G 1$ peak at the end of the first light-dark cycle.

Samples from the second light-dark cycle basically followed the same pattern (Fig. 5, Hour 25 to 32). A different feature was noticed regarding the migration of the $S$ peak. The histogram at Hour 31 indicated that the $S$ peak was about to complete DNA synthesis, and it partiaily jointed with the $G 2+M$ peak. This happened about 5 h early compared to the equivalent histogram in the first light-dark cycle (Fig. 5, Hour 13). Also, a second $S$ peak was observed at Hour 32 in the 2nd light-dark cycle.

The 'stationary' samples were taken from a culture in

Table 3. Heterocapsa triquetra. Daily mean growth rates $\left(\mathrm{d}^{-1}\right)$ estimated from cell cycle analysis and cell counts

\begin{tabular}{|c|c|c|c|c|c|c|}
\hline \multirow{2}{*}{$\begin{array}{l}\text { From cell cycle analysis } \\
\text { Sampling } \\
\text { schedule }\end{array}$} & \multicolumn{3}{|c|}{ 'Exponential' samples } & \multicolumn{3}{|c|}{ 'Stationary' samples } \\
\hline & $\begin{array}{l}\text { Without } \\
\text { curve } \\
\text { fitting }\end{array}$ & $\begin{array}{c}\text { Polynomial } \\
- \\
\text { iteration }\end{array}$ & $\begin{array}{c}\text { Polynomial } \\
+ \\
\text { iteration }\end{array}$ & $\begin{array}{l}\text { Without } \\
\text { curve } \\
\text { fitting }\end{array}$ & $\begin{array}{c}\text { Polynomial } \\
- \\
\text { iteration }\end{array}$ & $\begin{array}{c}\text { Polynomial } \\
+ \\
\text { iteration }\end{array}$ \\
\hline Every hour & 0.55 & 0.55 & 0.51 & - & - & - \\
\hline Every hour a & 0.56 & 0.55 & 0.52 & - & & - \\
\hline Every $2 \mathrm{~h}$ & 0.57 & 0.54 & 0.52 & 0.13 & 0.11 & 0.11 \\
\hline Every $3 \mathrm{~h}$ & 0.59 & 0.60 & 0.60 & - & - & - \\
\hline \multicolumn{7}{|l|}{ From cell counts } \\
\hline
\end{tabular}


its second day of the stationary phase (Fig. 4, lower panel). The growth rate for the stationary phase estimated by linear regression is virtually zero (Table 3 ). DNA histograms from 'stationary' samples reflect this fact with dominant $G 1$ peaks throughout the 24 h cycle (Fig. 6). However, small peaks composed of $G 2+M$ cells could still be found sometimes during the day. The size of the $G 2+M$ peak performed a periodic change and became most noticeable at Hours 19 and 20 which was about 3 to $5 \mathrm{~h}$ before the end of the dark period. No $S$ peak could easily be seen in these histograms.

Deconvolving these histograms generated quantitative estimates for $G 1, S$, and $G 2+M$ phase fractions. For all samples, fitted multiple normal curves simulated the real data points very well. The standard errors of the area under $G 1$ normal curves ranged from 1.1 to $15 \%$ of the estimated area, and the standard errors of $G 2+M$ areas ranged from 3.4 to $33 \%$. Plotting phase fractions
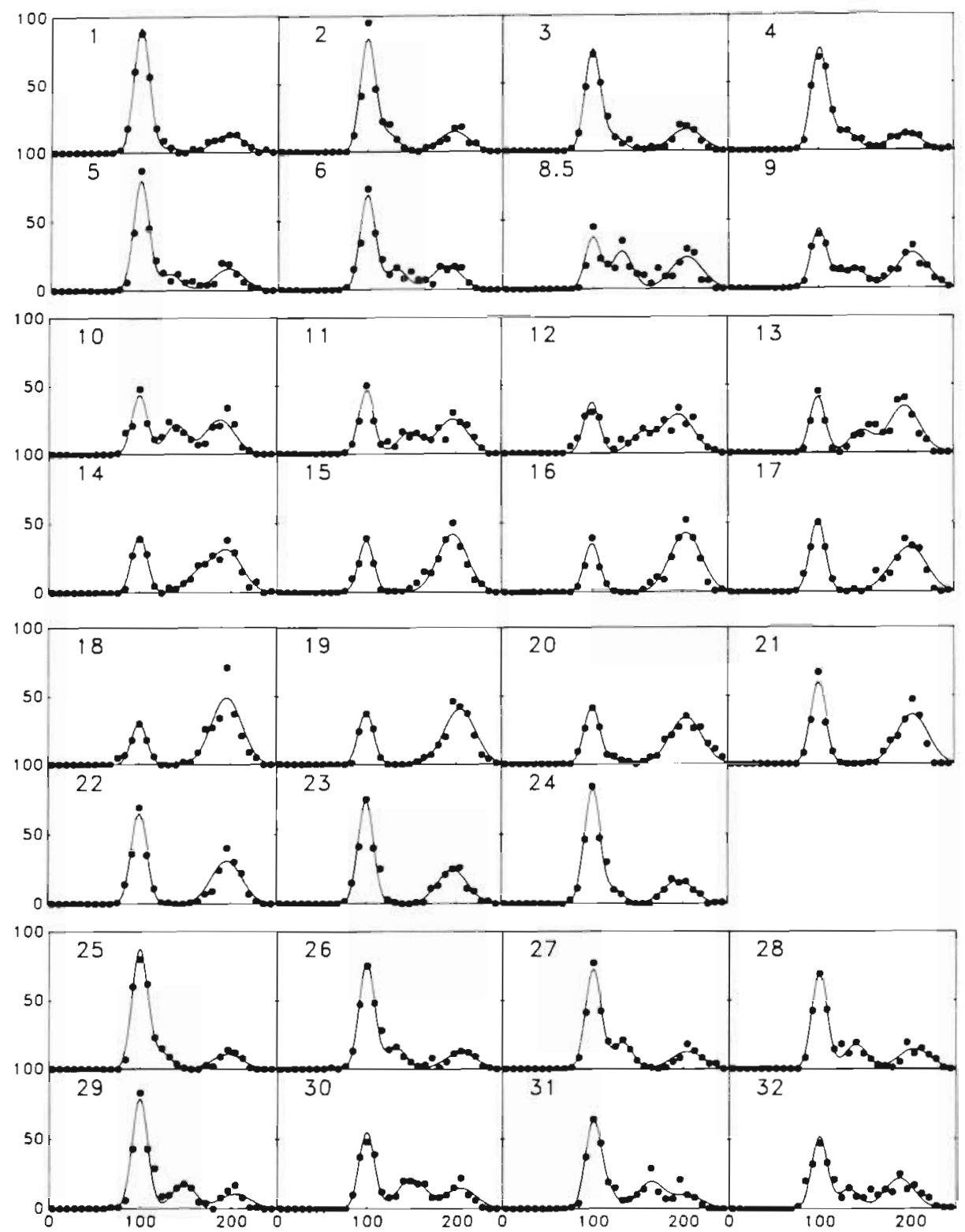

RELATIVE DNA

Fig. 5. Heterocapsa triquetra. DNA histograms from 'exponential' samples. Samples were taken from a culture for 32 consecutive hours. $y$-axes: number of nuclei. Number in each panel indicates how many hours after the onset of the light period on Day 8 that sample was taken. One sample at Hour 7 was missed. The sample at Hour 25 is acutally $1 \mathrm{~h}$ after the onset of the light period on Day 9 . Points $(\bullet$ were measured by microfluorometry; solid curves were fitted by deconvolution procedures with $\mathrm{CV}=8.5 \%$ 


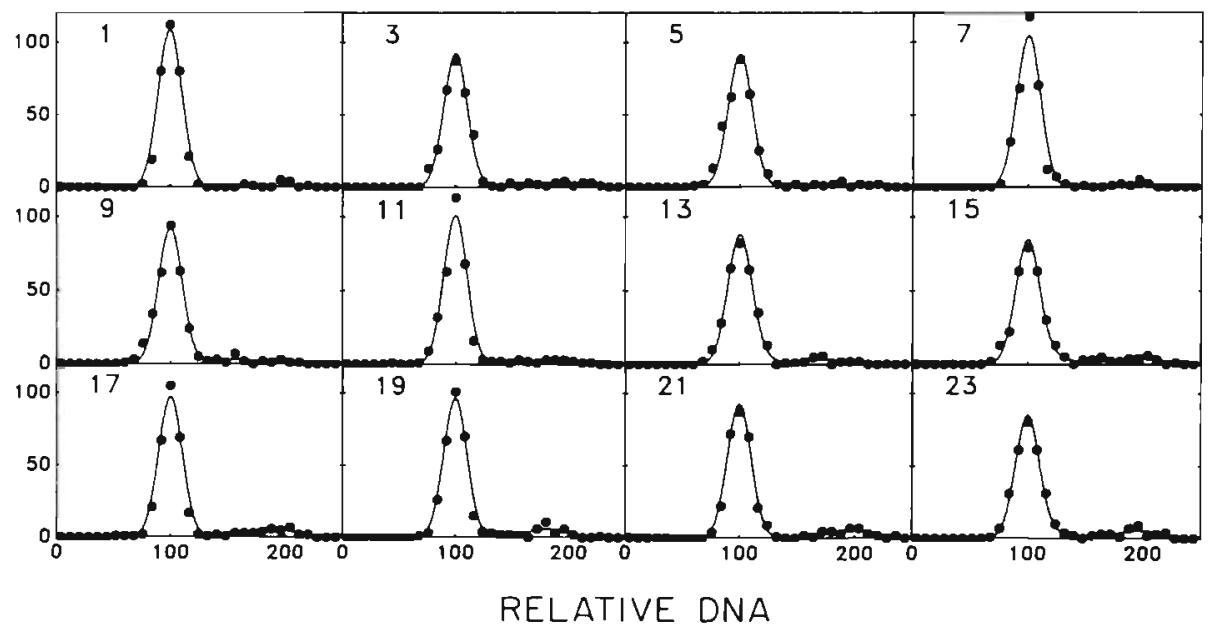

Fig. 6. Heterocapsa triquetra. DNA histograms from 'stationary' samples. Samples were taken from a culture in stationary phase for one 24 h cycle. $y$-axes: number of nuclei. Number in each panel indicates how many hours after the onset of the light period on Day 8 that sample was taken. Points $(\bullet)$ were measured by microfluorometry; solid curves were fitted by deconvolution procedures with CV $=10.3 \%$

against time summarized these 2 partially synchronized cell division cycles (Figs. 7 and 8). The diel rhythm in each phase fraction was obvious. In both experiments, $G 2+M$ phase fractions peak in the middle of the dark period, and, apparently, mitosis occurs near the dark-light transition point. The $S$ fraction of 'exponential' samples reached the highest point about $5 \mathrm{~h}$ before the onset of the dark period, but the $S$ maximum of 'stationary' samples appeared at the

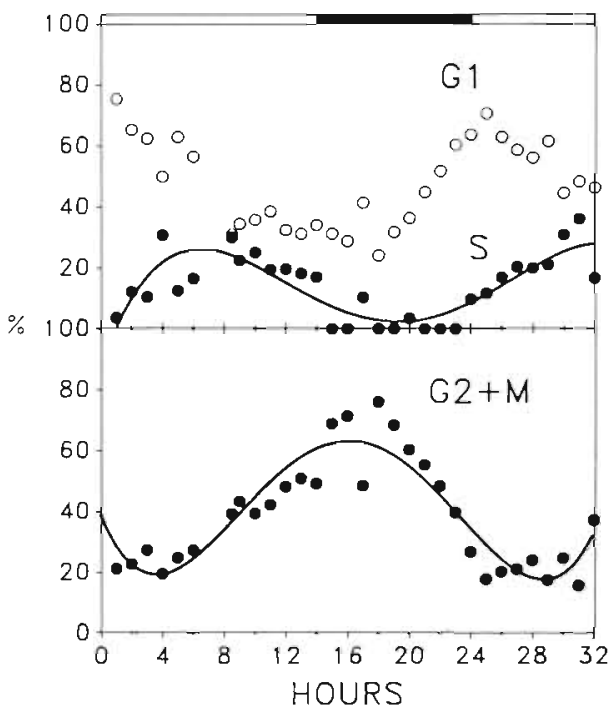

Fig. 7 Heterocapsa triquetra phase fractions for 'exponential' samples. Upper panel: (o) G1 phase fractions at different times; $(\bullet)$ phase fractions. Solid curve is a fitted 4 th degree polynomial using all data points. Lower panel: (•) $G 2+M$ phase fractions. Solid curve is a fitted 4 th degree polynomial using all data points. Dark bar at top: dark period during a 24 h cycle beginning of the dark period. The polynomial regression curves fitted data points reasonably well. Nevertheless, the maxima of fitted curves were different from the maxima indicated by data points.

Several methods were used to calculate the duration of $S$ and $G 2+M$ phases and the daily mean population growth rate, $\mu$ (Table 3 ). Various ways of calculating growth rate did not give significantly different results. Although the duration of the $S$ phase varied with differ-

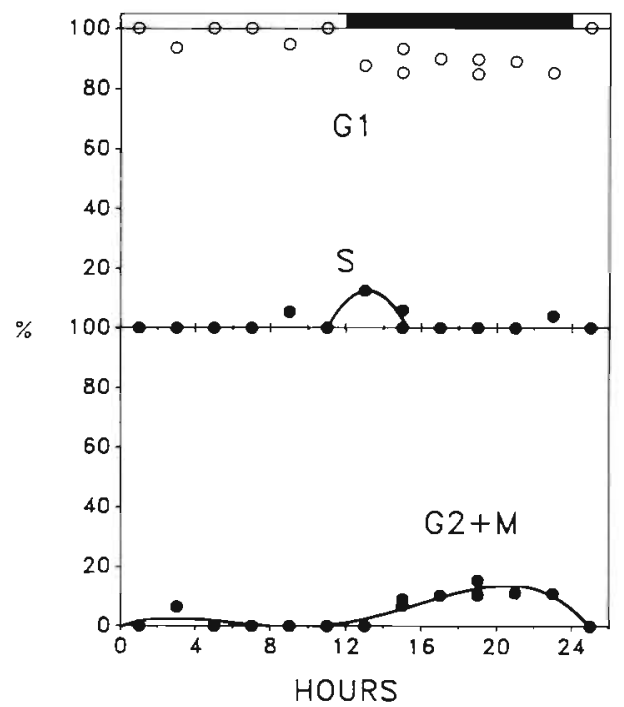

Fig. 8. Heterocapsa triquetra phase fractions for 'stationary' samples. One extra histogram was measured for Hours 11, 15, and 19 as replicates. Upper panel: (o) G1 phase fractions at different times; $(\bullet) S$ phase fractions. Solid curve is a fitted 2 nd degree polynomial using 5 data points between Hour 11 and 15. Lower panel: $(\bullet) G 2+M$ phase fractions. Solid curve is a fitted 4 th degree polynomial using all data points. Dark bar at top: dark period during a $24 \mathrm{~h}$ cycle 
Table 4. Heterocapsa triquetra. Durations of $S$ and $G 2+M$ phases (h) obtained by the iterative method

\begin{tabular}{|lcc|}
\hline Sampling schedule & $T_{S}$ & $\mathrm{~T}_{\mathrm{G} 2 \mathrm{M}}$ \\
\hline 'Exponential' samples: & & \\
$\quad$ Every hour & 3.8 & 16.6 \\
Every 2 h & 4.4 & 16.6 \\
$\quad$ Every 3 h & 2.8 & 15.0 \\
'Stationary' samples: & & \\
$\quad$ Every 2 h & 4.3 & 10.6 \\
\hline
\end{tabular}

ent sampling schedules in 'exponential' samples (Table 4), no substantial diversion was found in estimating $\mu$ when the sampling interval was increased to $3 \mathrm{~h}$. In general, growth rates from cell cycle analysis were higher than growth rate from cell counts. For 'exponential' samples, if we take $\mu$ calculated by the iterative method $\left(0.51 \mathrm{~d}^{-1}\right)$ and compare it to the growth rate estimated by cell counts from Day 8 to $10\left(0.38 \mathrm{~d}^{-1}\right)$, the $\mu$ from the iterative method overestimated $\mu$ from cell counts by $0.13 \mathrm{~d}^{-1}$. Similarly, $\mu$ from the cell cycle analysis for 'stationary' samples overestimated $\mu$ from cell counts by $0.11 \mathrm{~d}^{-1}$.

\section{DISCUSSION}

The variation in fluorescence intensity of samples measured by our microfluorometry system is more than 4 times larger than that measured by flow cytometry. Possible causes include the flickering of the arc in the mercury lamp (Ploem et al. 1974), the resolution of the video digitizer, and the relatively small sample size. The CV of fluorspheres measured in this study was $5 \%$ higher than the factory-measured CV (Table 1). Similarly, the fluorescence $\mathrm{CV}$ of CRBCs measured by flow cytometry was only $0.78 \%$ (Lee et al. 1984). However, our CV for CRBC is within the normal range for microfluorometry since the CV of DAPI-stained CRBC measured by Coleman et al. (1981) is between 2.83-and $6.97 \%$.

For rat liver nuclei, diploid nuclei had a higher CV (Table 1). This might be caused by the fact that we did not try to separate nuclei of diploid liver cells from nuclei of other tissues such as blood. The DNA histogram of rat liver nuclei indicated that there exists a linear relation between the actual cellular DNA content and the fluorescence emitted from the DAPI-DNA complex (Table 1). However, unlike similar results obtained from flow cytometry (Lee et al. 1984), the tetraploid:diploid and octaploid:tetraploid DNA ratios measured by microfluorometry were not exactly 2 (Coleman et al. 1981). In DAPI-stained Heterocapsa triquetra, the $(G 2+M): G 1$ DNA ratio ranged from 1.87 to 2.09 . We think that these results justify the need for using a more flexible method to define the position of $G 2+M$ peak in deconvolving DNA histograms. Further, the $\mathrm{CV}$ value of cellular DNA content varied with each different cell types.

Although DAPI stain worked very well in a wide range of concentrations $\left(0.5\right.$ to $\left.5 \mu \mathrm{g} \mathrm{ml}^{-1}\right)$, unacceptable results did occur when dye concentration was too high (Fig. 2f). This could be because other cell components such as microtubules (Bonne et al. 1985), were stained by DAPI under high concentrations. Since there is no assurance that the disappearance of specificity for DNA occurs at the same dye concentration for different cell types, various concentrations should be tested whenever a new species is required to be stained for DNA histograms.

Several ways have been suggested for deconvolving DNA histograms. The multiple normal curve fitting (Fried 1976) used in this study fitted the actual data points very well. An advantage of this method is its flexibility in dealing with partially synchronized cell cyles (Dean 1985). Although this method tends to overestimate $G 1$ and $G 2+M$ phase fractions, it should have a smaller effect on the estimated growth rate. If the overestimation is consistent for all DNA histograms, according to Carpenter \& Chang's (1988) model, an overestimated $G 1$ phase fraction means that cells in the first few compartments of the $S$ phase are now regarded as $G 1$ cells, but the remaining $S$ compartments together with $G 2+M$ compartments still form a terminal event with a shorter duration. Consequently, both $\left(T_{S}+T_{G 2 M}\right)$ and $\left(f_{S}+f_{G 2 M}\right)$ will be underestimated. By the equation for growth rate estimation, these 2 biases introduced by an overestimated $G 1$ phase fraction will cancel each other and generate a correct $\mu$. For the same reason, in case these 2 biases do not cancel each other exactly, due to unequal $G 1$ overestimations for different histograms, the biases from overestimated $f_{G 1}$ 's should still be reduced by the computational procedure for $\mu$. In general, mathematical errors in estimating phase fractions by any method are considered less than sampling and measuring errors (Dean 1985)

The polynomial regression is an effective way to smooth out the phase fraction curves (Figs. 7 and 8 ). This method is selected because it is theoretically simple, and computational procedures are included in almost all statistical software packages. One minor problem is that some phase fraction curves, such as the $S$ fraction curve of 'stationary' samples (Fig. 8), cannot be simulated well by a polynomial function. Instead of using all the data points from the $24 \mathrm{~h}$ cycle, we were forced to choose points near the maximum to get a statistically meaningful fit.

From our results, sampling intervals as long as $3 \mathrm{~h}$ could still generate growth rate estimates close to $\mu$ 
calculated from hourly samples (Tables 3 and 4 ). Since a long terminal event relative to the sampling interval can improve the accuracy of growth rate estimates (McDuff \& Chisholm 1982), the $20 \mathrm{~h}$ terminal event should allow us to reduce sampling frequencies. In our experience, sampling intervals longer than $3 \mathrm{~h}$ would generate less than 8 data points on phase fraction curves. When applying the iterative method, such few points were sometimes unable to produce a statistically significant polynomial.

Our estimates for $\mu$ were about $0.1 \mathrm{~d}^{-1}$ higher than growth rate estimated by cell counts. We do not think that this is a severe shortcoming of this method, especially when the growth rate range of interest in the field is more than an order of magnitude. Part of the overestimation observed may come from the fact that this cell cycle method overlooks cell death completely if the death rate is constant for all cell cycle compartments. Since the growth rate from cell counts is the net growth rate, which has already taken the death rate into account, $\mu$ calculated from the cell cycle method would inevitably be higher. This explanation is supported by DNA histograms from 'stationary' samples (Fig. 6). From the periodic change in sizes of the $G 2+M$ peak, mitosis must occur although there is no variation in population size estimated by cell counts. An unexpected result from the dye concentration experiment also seems to suport this point. Note that our samples were from the stationary phase of the culture (Fig. 4, upper panel, Day 13) so the growth rate from cell count should be close to zero. From the histograms (Fig. $2 e$ ), a weil-formed $G 2+M$ peak indicated that these cells were likely to divide soon unless they were trapped in the $G 2$ phase. Since cells of another dinoflagellate. Amphidinium carteri, cannot be trapped in the G2 phase in either light- or nitrogenlimited stationary phase (Olson \& Chisholm 1986), the disagreement found between our DNA histograms and daily cell counts implies that the growth of some individuals of the stationary population was balanced by the death of some other individuals. It is possible that similar cell death also occurs in an exponentially growing population.

From the above discussion, several things have been learned in applying cell cycle analysis to phytoplankton populations. As predicted by McDuff \& Chisholm (1982), a long terminal event indeed improves the precision and can tolerate longer sampling intervals (Table 3). The sum of $S, G 2$, and $M$ phases is a better terminal event than the $G 2+M$ phase because the variation is the smallest for the $G 1$ phase fraction in the deconvolution procedure. At any time, the sum of $f_{S}$ and $f_{G 2 M}$ will have the same small variation since this sum is nothing but $\left(1-f_{G 1}\right)$. On the other hand, since maxima on $f_{5}$ and $f_{G 2 M}$ must be located to obtain the duration of the terminal event, samples have to be taken close enough to describe these maxima. From our results, an interval of $2 \mathrm{~h}$ should provide a good balance between a small number of samples and an accurate estimate for the duration of the terminal event. Also, this study suggests that growth rates calculated with the iterative method do not differ considerably from those calculated without the iterative method (Table 3 ). It seems that the assumption of $r\left(t_{1}\right)=r\left(t_{2}\right)=0$ is good enough, and a simpler version of computational procedures can be used in future applications. Since the growth rates covered by our experiments are low to moderate, the question of whether iteration is required by a fastergrowing population still needs further investigation.

Acknowledgements. This research was supported by NSF grants OCE8515730 and OCE8710798 to E. J. C. We thank A. W. Coleman of Brown University for advising us on staining techniques, and D. C. Watkins of the Department of Pharmacological Sciences, SUNY at Stony Brook for providing rat livers. Contribution No. 596 from the Marine Sciences Research Center.

\section{LITERATURE CITED}

Bonne, D., Heusèle, C., Simon, C., Pantaloni, D. (1985). 4'-6diamidino-2-phenylindole, a fluorescent probe for tubulin and microtubules. J. Biol. Chem. 260: 2819-2825

Brunk, C. F., James, T W. (1977). Intracellular and in vitro fluorescence of the DNA specific probe: 4'6-diamidino-2phenylindole (DAPI). J. Cell Biol. 75: 136a

Carpenter, E. J., Chang, J. (1988). Species-specific phytoplankton growth rates via diel DNA synthesis cycles. I. Concept of the method. Mar. Ecol. Prog. Ser. 43: 105-111

Coats, D. W. Heinbokel, J. F. (1982). A study of reproduction and other life cycle phenomena in planktonic protists using an acridine orange fluorescence technique. Mar. Biol. 67: 71-79

Coleman, A. W., Maguire, M. J., Coleman, J. R. (1981). Mithramycin- and 4'-6-diamidino-2-phenylindole (DAPI)DNA staining for fluorescence microspectrophotometric measurement of DNA in nuclei, plastids, and virus particles. J. Histochem. Cytochem. 29: 959-968

Dean, P. N. (1985). Methods of data analysis in flow cytometry. In: Van Dilla, M. A., Dean, P. N., Laerum, O. D., Melamed, M. R. (eds.) Flow cytometry: instrumentation and data analysis. Academic Press, London, p. 195-221

Dolbeare, F, A. (1981). Fluorometric quantification of specific chemical species in single cells. In: Wehry, E. L. (ed.) Modern fluorescence spectroscopy. Plenum Press, New York, p. 251-293

Elser, M. M., Smith, W. O. (1985). Phased cell division and growth rate of a planktonic dinoflagellate, Ceratium hirundinella, in relation of environmental variables. Arch. Hydrobiol. 104: 477-491

Fried, J. (1976). Method for the quantitative evaluation of data from flow microfluorometry. Comp. Biomed. Res. 9: 263-276

Goldman, J. C., McCarthy, J. J. (1978). Steady state growth and ammonium uptake of a fast-growing marine diatom. Limnol. Oceanogr. 23: 695-703

Guillard, R. R. L. (1973). Division rates. In: Stein, J. R. (ed.) Handbook of phycological methods: culture methods and 
growth measurements. Cambridge University Press, London, p. 289-312

Guillard, R. R. L., Ryther, J. H. (1962). Studies of marine planktonic diatoms: I. Cyclotella nana Hustedt and Detonula confervacea (Cleve) Gran. Can. J. Microbiol. 8: 229-239

Kapuścinski, J., Skoczylas, B. (1977). Simple and rapid fluorimetric method for DNA microassay. Analyt. Biochem. 83: 252-257

Lee, G. M., Thornthwaite, J. T., Rasch, E. M. (1984). Picogram per cell determination of DNA by flow cytofluorometry. Analyt. Biochem. 137: 221-226

Leeson, C. R., Leeson, T. S., Paparo, A. A. (1985). Text book of histology. W. B. Saunders Company, Philadelphia

McDuff, R. E., Chisholm, S. W. (1982). The calculation of in situ growth rates of phytoplankton populations from fractions of cells undergoing mitosis: a clarification. Limnol. Oceanogr. 27: 783-788

Mitchison, J. M. (1971). The biology of the cell cycle. Cambridge University Press, London

Olson, R. J., Chisholm, S. W. (1986). Effects of light and nitrogen limitation on the cell cycle of the dinoflagellate Amphidinium carteri. J. Plankton Res. 8: 785-793

Olson, R. J., Frankel, S. L., Chisholm, S. W., Shapiro, H. M. (1983). An inexpensive flow cytometer for the analysis fluorescence signals in phytoplankton: chlorophyll and DNA distributions. J. exp. mar. Biol. Ecol. 68: 129-144

Otto, F., Tsou, K. C. (1985). A comparative study of DAPI, DIPI, and Hoechst 33258 and 33342 as chromosomal DNA stains. Stain Technol. 60: 7-11

Ploem, J. S., de Sterke, J. A., Bonnent, J., Wasmund, H. (1974). A microspectrofluorometer with epi-illumination operated under computer control. J. Histochem. Cytochem. 22: 668-677

Sokal, R. R., Rohlf, F. J. (1981). Biometry, 2nd edn. W. H Freeman and Company, San Francisco

Waterman, M. S. (1974). A restricted least squares problem Technometrics 16: 135-136

Weiler, C. S., Chisholm, S. W. (1976). Phased cell division in natural populations of marine dinoflagellates from shipboard cultures. J. exp. mar. Biol. Ecol. 25: 239-247

Williamson, D. H., Fennell, D. J. (1975). The use of fluorescent DNA-binding agent for detecting and separating yeast mitochondrial DNA. In: Prescott, D. M. (ed.) Methods in cell biology. Academic Press, New York, p. 335-351

Yentsch, C. M., Mague, F. C., Horan, P. K., Muirhead, K. (1983). Flow cytometric DNA determinations on individual cells of the dinoflagellate Gonyaulax tamarensis var. excavata. J. exp. mar. Biol. Ecol. 67: 175-183

This article was presented by Dr N. S. Fisher; it was accepted for printing on March 4, 1988 